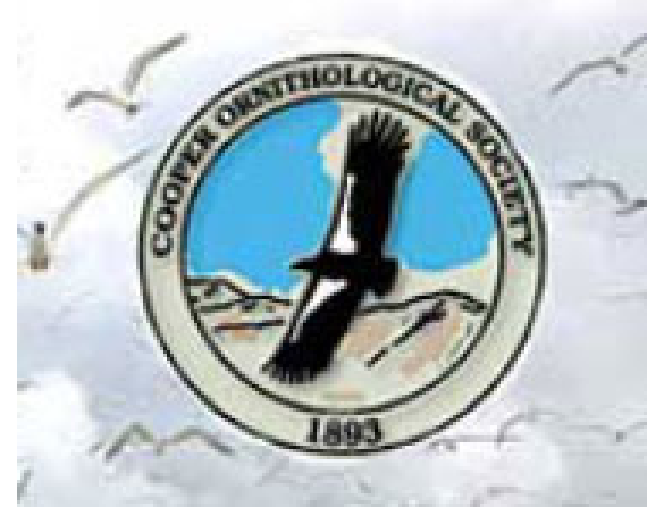

A Comparison of the Characteristics and Fate of Barrow's Goldeneye and Bufflehead Nests in Nest Boxes and Natural Cavities

Author(s): Matthew R. Evans, David B. Lank, W. Sean Boyd and Fred Cooke

Reviewed work(s):

Source: The Condor, Vol. 104, No. 3 (Aug., 2002), pp. 610-619

Published by: University of California Press on behalf of the Cooper Ornithological Society

Stable URL: http://www.jstor.org/stable/1370741

Accessed: $21 / 06 / 2012$ 12:20

Your use of the JSTOR archive indicates your acceptance of the Terms \& Conditions of Use, available at http://www.jstor.org/page/info/about/policies/terms.jsp

JSTOR is a not-for-profit service that helps scholars, researchers, and students discover, use, and build upon a wide range of content in a trusted digital archive. We use information technology and tools to increase productivity and facilitate new forms of scholarship. For more information about JSTOR, please contact support@jstor.org.

University of California Press and Cooper Ornithological Society are collaborating with JSTOR to digitize, preserve and extend access to The Condor. 


\title{
A COMPARISON OF THE CHARACTERISTICS AND FATE OF BARROW'S GOLDENEYE AND BUFFLEHEAD NESTS IN NEST BOXES AND NATURAL CAVITIES
}

\author{
Matthew R. Evans ${ }^{1,3}$, David B. Lank ${ }^{1}$, W. Sean Boyd ${ }^{2}$ and Fred Cooke ${ }^{1}$ \\ ${ }^{\prime}$ Centre for Wildlife Ecology, Simon Fraser University, 8888 University Drive, Burnaby, BC V5A 1S6, Canada \\ ${ }^{2}$ Canadian Wildlife Service, Pacific Wildlife Research Centre, RR1, 5421 Robertson Road, \\ Delta, BC V4K 3N2, Canada
}

\begin{abstract}
Barrow's Goldeneye (Bucephala islandica) and Bufflehead (B. albeola) are cavity-nesting waterfowl that have received considerable attention in studies using nest boxes, but little is known about their nesting ecology in natural cavities. We found larger clutch size, lower nesting success, and different major predators for Barrow's Goldeneyes nesting in boxes versus those nesting in natural cavities, but few differences for Bufflehead. These differences are attributed to the location and physical differences between Barrow's Goldeneye nest boxes and natural cavities that affect their conspicuousness to predators and conspecific nest-parasitizing females. Goldeneye boxes were concentrated in highly visible locations such as trees at water or forest edge. Natural cavity nests, on the other hand, were often abandoned Pileated Woodpecker (Dryocopus pileatus) cavities, which were more dispersed throughout the forest interior and concealed under dense canopy cover. Bufflehead natural cavity nests were typically closer to edges, which may account for their similarity with boxes. We conclude that in some respects, studies of Barrow's Goldeneye that use nest boxes may not be representative of birds nesting in natural cavities, whereas those of Bufflehead are more likely to be so.
\end{abstract}

Key words: Barrow's Goldeneye, Bufflehead, natural cavities, nest boxes, nest success, predation.

Comparación de la Ecología de Nidificación de Bucephala islandica y B. albeola en Nidos Artificiales y en Cavidades Naturales

\begin{abstract}
Resumen. Los especies de patos Bucephala islandica y B. albeola anidan en cavidades, por lo que con frecuencia han sido estudiadas usando nidos articificales, pero poco se conoce sobre su ecología de nidificación en cavidades naturales. Los individuos de $B$. islandica que anidan en nidos artificiales presentaron nidadas más grandes, menor éxito reproductivo y distintos depredadores que los individuos que anidan en cavidades naturales, pero detectamos pocas diferencias para $B$. albeola. Estas diferencias son atribuidas a la ubicación y a las diferencias físicas entre los nidos artificiales y las cavidades naturales de $B$. islandica que afectan su visibilidad para deprededores y hembras coespecíficas que parasitan los nidos. Los nidos artificiales de $B$. islandica estuvieron concentrados en lugares muy visibles como árboles al borde del bosque o a la orilla del agua. Por el contrario, las cavidades naturales frecuentemente fueron cavidades abandonadas de Dryocopus pileatus, las cuales se presentaron más dispersas por el interior del bosque y ocultas bajo un dosel denso. Las cavidades naturales de $B$. albeola se ubicaron típicamente más cerca del borde, lo que tal vez explica la semejanza con los nidos artificiales. Concluimos que en algunos casos, los estudios de $B$. islandica que utilizan nidos artificiales pueden no ser representativos de individuos que anidan en cavidades naturales, mientras que los estudios de B. albeola probablemente sí sean más representativos.
\end{abstract}

\section{INTRODUCTION}

Many ornithological studies have used nest boxes to examine the breeding biology and life histories of cavity-nesting species. Research using nest boxes includes perhaps the oldest on-

Manuscript received 14 June 2001; accepted 30 April 2002.

${ }^{3}$ E-mail: mrevans@sfu.ca going field studies on any animal species, beginning in the Netherlands in the 1920s and in Britain in the 1940s (Møller 1989) and has influenced theories in avian biology, including population regulation (Lack 1954, Krebs 1971), life history evolution (Lack 1954, Boyce and Perrins 1987), quantitative genetics (van Balen 1984), and sexual selection (Alatalo et al. 1986). At least 65 species of cavity-nesting 
birds in North America and Europe use boxes (Eadie et al. 1998).

Nest boxes are also valuable for conservation programs aimed at augmenting target species' abundance, having increased populations for 22 of 23 studied species (Eadie et al. 1998). Highly successful programs have included Eastern Bluebirds (Sialia sialis, Gowaty and Bridges 1991), Wood Ducks (Aix sponsa, Nichols and Johnson 1990), and American Kestrels (Falco sparverius; Hamerstrom et al. 1973).

Despite the utility of nest boxes for birds, researchers, and managers, the behavior and demographics of birds nesting in boxes are likely to differ from those of birds nesting in natural sites (Nilsson 1986). Nest box studies may be biased in two important ways: they often reduce nest predation levels to a fraction of their natural levels, and they reduce ectoparasite loads when researchers consistently remove old nests at the end of each breeding season (Møller 1989). In fact, it has long been believed that cavity nesters have higher nesting success rates than do ground-nesting birds (Lack 1954), a belief that has arisen primarily from the results of nest box studies. Some now argue that this belief may be inaccurate, as studies of populations using natural cavities have begun to show (Purcell et al. 1997). Nilsson (1984a) found nest predation to be $62 \%$ lower in nest boxes than cavities for five passerine species, and nesting success in natural holes was nearly identical to that of open-nesting species (Nilsson 1986). Other studies have reported that nest-box populations experience lower rates of predation, lay larger clutches (Robertson and Rendell 1990), and fledge more young (Nilsson 1986, Kuitunen and Aleknonis 1992) than populations in natural sites.

Nest boxes may alter other key ecological processes such as population dynamics and intraspecific social interactions like conspecific brood parasitism (Møller 1989, Eadie et al. 1998). The addition of artificial nesting structures may also produce artificially high densities of breeding birds, which may have negative influences on other species' breeding ecology, such as increasing competition for nest sites. In some species, these changes may even lead to precipitous declines in productivity and result in population instability and decline (Eadie et al. 1998). More information on birds nesting in cavities will allow further understanding of the factors that regulate populations of secondary cav- ity nesters and influence community structure (Purcell et al. 1997).

Barrow's Goldeneye (Bucephala islandica) and Bufflehead (B. albeola) are cavity-nesting waterfowl that have received considerable attention in studies using boxes (Gauthier 1985, Savard 1986, Eadie 1989, Thompson 1996). However, little is known about the nesting ecology of these birds in natural cavities. This is also true for Common Goldeneyes (B. clangula), which now nest predominately in nest boxes across their range in northwestern Europe (Eriksson 1982, Fredga and Dow 1984). The purpose of this study was to compare nest characteristics, fate, and sources of predation of Barrow's Goldeneyes and Bufflehead breeding in nest boxes and natural cavities.

\section{METHODS}

\section{STUDY AREA}

This study was conducted between April and September, 1997-1999, on approximately 200 $\mathrm{km}^{2}$ in the Cariboo Parklands, $45 \mathrm{~km}$ west of Williams Lake, British Columbia $\left(52^{\circ} 07^{\prime} \mathrm{N}\right.$, $122^{\circ} 27^{\prime} \mathrm{W}$ ). The area is characterized by a rich mixture of naturally fragmented deciduous and coniferous forest among grasslands and prairie pothole wetlands. Deciduous species include trembling aspen (Populus tremuloides) and balsam poplar (Populus balsamifera), interspersed with coniferous Douglas-fir (Pseudotsuga menziesii), white spruce (Picea glauca), and lodgepole pine (Pinus contorta). The Barrow's Goldeneye and Bufflehead populations in this area have been well studied (Erskine 1972, Gauthier 1985, Savard 1986, Eadie 1989, Thompson 1996).

\section{NEST BOXES}

Barrow's Goldeneye and Bufflehead nest boxes have existed in the study area since 1981 (Savard 1986). In 1998 and 1999, we repaired or replaced boxes worn by weather or destroyed by predators (ca. 15\%, annually) and added boxes to some areas. By 1999, 234 goldeneye boxes and 118 Bufflehead boxes were available. These boxes varied in their dimensions for both species as a result of the differing needs of previous studies (Table 1) and were located 3-6 m above ground in various species of trees. No predatorexclusion devices were used and old nests were not removed between breeding seasons. Nest boxes were accessed using ladders. 
TABLE 1. Nest box dimensions and number of boxes made available each year to Barrow's Goldeneye and Bufflehead at Riske Creek, British Columbia, Canada, 1997-1999.

\begin{tabular}{lccccc}
\hline \hline \multicolumn{1}{c}{ Species } & $\begin{array}{c}\text { Number of } \\
\text { boxes available }\end{array}$ & $\begin{array}{c}\text { Length } \times \text { width } \\
\times \text { height }(\mathrm{cm})\end{array}$ & Volume $(\mathrm{L})$ & $\begin{array}{c}\text { Floor area } \\
\left(\mathrm{cm}^{2}\right)\end{array}$ & Entrance size $(\mathrm{cm})$ \\
\hline Barrow's Goldeneye & & & & & \\
& 139 & $39 \times 25 \times 26$ & 25.4 & 650 & $11 \times 13$ \\
& 71 & $50 \times 25 \times 28$ & 35.0 & 700 & $11 \times 10$ \\
Bufflehead & 24 & $41 \times 25 \times 26$ & 26.7 & 650 & $12 \times 12$ \\
& & & & & \\
& 43 & $28 \times 15 \times 15$ & 6.3 & 225 & $7 \times 7$ \\
& 54 & $32 \times 18 \times 20$ & 11.5 & 360 & $8 \times 8$ \\
& 21 & $28 \times 18 \times 18$ & 9.1 & 324 & $8 \times 8$ \\
\hline
\end{tabular}

Females were captured on the nest or wetland, banded, and marked with plastic nasal tags of different shapes and colors for individual identification (Savard 1986). Known multiple observations for the same female in successive years were excluded from the analysis, although some birds remained unmarked (fewer than $20 \%$ each year) and may have been included more than once.

\section{NATURAL CAVITIES}

Two techniques were used to locate natural cavity nest sites in April and May of each year. First, thorough searches were conducted through forest stands surrounding lakes that contained paired birds. Searches were performed along ad hoc transects with 2-4 persons spread out at ca. 10 -m distances, walking perpendicular from the water's edge for ca. $500 \mathrm{~m}$. Second, natural cavity nests were located by following females returning to nest sites to incubate after feeding. This method proved to be more effective in locating cavity nests ( $n=31$ of 41 goldeneyes, and 65 of 100 Bufflehead cavity nests) and had the advantage of being unbiased with respect to our choice of habitat types in which to conduct transect searches. However, it must be acknowledged that this search technique can be biased toward successful females. Since most box-nesting females carried individual nasal tags, we directed our efforts at females known not to be incubating in boxes. Although some deserted and early-failing nests may have gone undetected, we feel confident that we located the nest sites (boxes or cavities) of over $90 \%$ of the breeding pairs for both species each year because few broods of unknown origin appeared on ponds at hatching.
Cavities were accessed using ladders, tree spikes, and climbing ropes, and were inspected using mirrors and flashlights. Two of the 41 goldeneye cavity nests had "open-top" entrances located in trees with broken tops, and were included in the analysis. No Bufflehead nests were found in open-top cavities.

\section{PHYSICAL CHARACTERISTICS OF NEST SITES}

We measured the following characteristics of each nest box and natural cavity: tree species, tree height, box or cavity height in tree, entrance hole dimensions (height and width), and distance of nest to the nearest water. We also measured the distances of nest sites from forest edge. Internal cavity measurements (depth, length, and width of floor) were measured to the nearest $\mathrm{cm}$ with measuring tapes, and cavity volume and floor area were then calculated using these values.

\section{REPRODUCTIVE VARIABLES}

All active nest sites (boxes and cavities) were checked every 4-7 days from mid-April to July. We measured the following reproductive variables for each nest: clutch size, hatching date, nesting success, source of predation, and identity of the incubating female. Clutch size refers to the number of eggs in the nest, which may have been laid by more than one female. Nests were tallied as successful if one or more eggs hatched, and success rates were estimated using Mayfield (1961).

\section{CONSPECIFIC NEST PARASITISM}

Conspecific nest parasitism occurs frequently in populations of goldeneyes and Bufflehead (Gauthier 1985, Eadie 1989). Detailed informa- 
TABLE 2. Physical characteristics (means \pm SE) of active Barrow's Goldeneye and Bufflehead nest sites in nest boxes and cavities, 1997-1999. Available but unused nest sites were not included in the analysis. Nest sites used more than once were included only once.

\begin{tabular}{|c|c|c|c|c|}
\hline & \multicolumn{2}{|c|}{ Barrow's Goldeneye } & \multicolumn{2}{|c|}{ Bufflehead } \\
\hline & Cavity & Nest box & Cavity & Nest box \\
\hline $\bar{n}$ & 41 & 174 & 100 & 46 \\
\hline \multicolumn{5}{|l|}{ Tree species used (\%) } \\
\hline Aspen & 72 & 66 & 81 & 91 \\
\hline Douglas-fir & 23 & 9 & 12 & 2 \\
\hline Lodgepole pine & 5 & 22 & 7 & 7 \\
\hline White spruce & 0 & 3 & 0 & 0 \\
\hline Tree height $(\mathrm{m})$ & $26.2 \pm 1.2$ & $13.3 \pm 0.3$ & $14.6 \pm 0.8$ & $13.6 \pm 0.7$ \\
\hline Nest height (m) & $12.0 \pm 0.8$ & $3.8 \pm 0.9$ & $6.6 \pm 0.4$ & $3.9 \pm 0.2$ \\
\hline Distance from water (m) & $89.7 \pm 13.0$ & $41.3 \pm 3.4$ & $37.1 \pm 5.5$ & $24.5 \pm 4.5$ \\
\hline Distance from edge $(\mathrm{m})$ & $36.3 \pm 24.9$ & $3.4 \pm 0.5$ & $3.5 \pm 1.0$ & $2.6 \pm 0.7$ \\
\hline Entrance size $(\mathrm{cm})$ & $14 \times 12$ & $11 \times 12$ & $9 \times 9$ & $8 \times 8$ \\
\hline Nest site volume (L) & $16.0 \pm 0.1$ & $28.6 \pm 0.4$ & $5.5 \pm 0.1$ & $8.7 \pm 0.1$ \\
\hline Nest floor area $\left(\mathrm{cm}^{2}\right)$ & $299 \pm 16$ & $641 \pm 6$ & $189 \pm 4$ & $293 \pm 4$ \\
\hline
\end{tabular}

tion on daily egg-laying rates in each nest site was not collected in this study, and therefore, we were unable to calculate accurate nest parasitism rates. However, since females of both species typically lay 8-10 eggs (Gauthier 1985, Eadie 1989), we considered nests containing more than 10 eggs to have been parasitized. Although this technique likely produced conservative estimates of nest parasitism, it allowed us to compare minimum estimates between nest types.

\section{STATISTICAL ANALYSES}

Average values of physical characteristics of nest sites did not differ significantly between years, so data were pooled. Two-tailed independent $t$-tests were used to compare the physical characteristics of box nests to cavity nests. Within a species, and nest type, there was no annual variation in clutch sizes, so data were pooled across years for analysis of each nest type. Hatching dates did not differ between box nests and cavity nests among the three years, and these data were also pooled across years for subsequent analysis. Multiway contingency data analysis (PROC CATMOD, SAS 2000) was used to examine associations among nest fate, nest type, and year. Backward elimination techniques were used to select the best log-linear model during this analysis. Within-year comparisons of nest fates between nest types were made using chi-square tests with Bonferroni adjustments ( $P=0.05 / n$ comparisons). Values reported are means \pm SE. A significance level of $P<$ 0.05 was used throughout the analyses.

\section{RESULTS}

\section{PHYSICAL CHARACTERISTICS OF NEST SITES}

Physical attributes of box nests and cavity nests are presented in Table 2. Natural nest cavities used by goldeneyes were twice as far from water $\left(t_{191}=-5.1, P<0.001\right)$, farther from forest edge $\left(t_{191}=-7.9, P<0.001\right)$, and located higher in trees $\left(t_{191}=-18.1, P<0.001\right)$ than box nests. The mean nest volume of goldeneye cavities was only about half the size of box nests $\left(t_{312}=10.6, P<0.001\right)$, as was the floor area $\left(t_{312}=20.5, P<0.001\right)$.

Nest cavities used by Bufflehead were also higher in trees $\left(t_{200}=-11.7, P<0.001\right)$ than box nests (Table 2). Although Bufflehead cavity nests were located farther from water than box nests $\left(t_{200}=-2.8, P<0.01\right)$, distances from the forest edge were similar $\left(t_{200}=-1.6, P<0.1\right)$. Bufflehead cavity nests had a smaller nest site volume $\left(t_{200}=16.3, P<0.001\right)$ and floor area $\left(t_{200}=16.9, P<0.001\right)$ than box nests. For both species, active natural cavities were most commonly found in aspen and Douglas-fir trees. Both species most commonly used nest boxes on aspen trees.

\section{CLUTCH SIZES}

Mean clutch sizes of goldeneyes were significantly larger in box nests than in cavity nests (box nests: $10.5 \pm 0.2$ eggs; cavity nests: $7.5 \pm$ $0.4 ; t_{239}=6.3, P<0.001$ ), but for Bufflehead, mean clutch sizes were similar in both nest types 

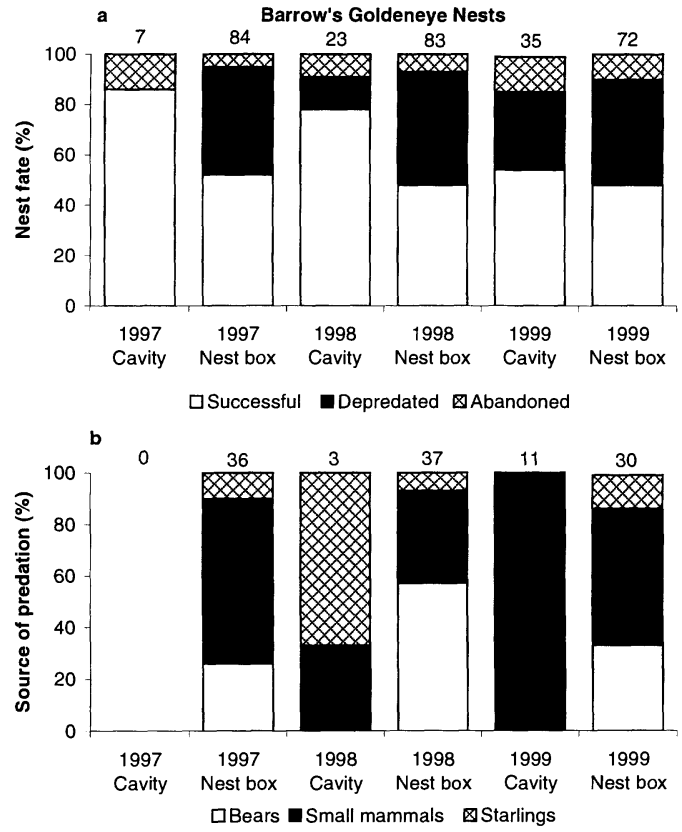

FIGURE 1. (a) Fates of Barrow's Goldeneye nests (successful, depredated, or abandoned) in boxes and natural cavities and (b) sources of nest predation from 1997-1999, at Riske Creek, British Columbia, Canada. Numbers above columns represent sample sizes.

(box nests: $8.4 \pm 0.3$ eggs; cavity nests: $8.5 \pm$ $\left.0.2 ; t_{179}=-0.6, P>0.4\right)$.

Twenty-five percent ( 60 of 234) of goldeneye box nests contained more than 10 eggs, compared to only $5 \%$ of cavity nests ( 2 of 41 ) indicating that nest parasitism was higher in box nests $\left(\chi_{2}^{2}=8.9, P<0.02\right)$. For Bufflehead, only $8 \%$ ( 9 of 118) of nests in boxes had more than 10 eggs, compared to $17 \%$ (17 of 100) of nests in cavities $\left(\chi_{2}^{2}=4.5, P<0.03\right)$.

\section{HATCHING DATES}

There were no differences between mean Julian hatching dates of nests in boxes compared to nests in cavities, for either species. The mean Julian hatching date for goldeneye eggs in box nests was $165.9 \pm 1.4$ (14 June) and $166.4 \pm$ 2.4 (15 June) in cavity nests $\left(t_{191}=-0.3, P>\right.$ 0.6 ). Bufflehead had mean Julian hatching dates of $169.3 \pm 0.6$ (18 June) for eggs in box nests, and $169.5 \pm 1.6$ (18 June) for eggs in cavity nests $\left(t_{109}=-0.2, P>0.7\right)$.

\section{NEST FATES}

The log-linear model examining associations between Barrow's Goldeneye nest fate, nest type,
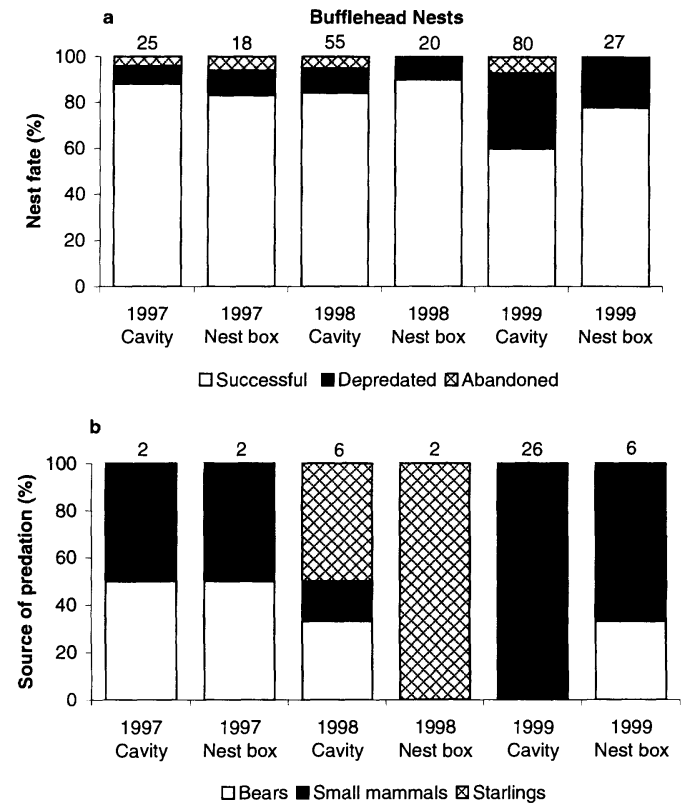

FIGURE 2. (a) Fates of Bufflehead nests (successful, depredated, or abandoned) in boxes and natural cavities and (b) sources of nest predation from 1997-1999, at Riske Creek, British Columbia, Canada. Numbers above columns represent sample sizes.

and year showed interactions between nest fate and nest type $\left(\chi_{2}^{2}=7.3, P<0.05\right)$, and nest fate and year $\left(\chi_{2}^{2}=12.4, P<0.01\right)$. Further analysis indicated that nest fates did not differ significantly among box nests throughout the study, nor did they differ among cavity nests between 1997 and 1998 (Fig. 1a). However, nesting success in cavities dropped from $86 \%$ in 1997 and $78 \%$ in 1998 to $54 \%$ in 1999 , as a result of higher levels of nest predation. Goldeneye nests in natural cavities had significantly higher nesting success rates than those in boxes in 1997 and 1998 (1997: $\chi_{2}{ }_{2}=7.7, P<0.02$; 1998: $\left.\chi_{2}{ }_{2}=8.6, P<0.01\right)$. However, no differences in nest fates were detected in $1999\left(\chi^{2}{ }_{2}=\right.$ 1.2, $P>0.4$; Fig. 1a).

For Bufflehead, the log-linear model showed an interaction between nest fates and year $\left(\chi^{2}{ }_{2}\right.$ $=14.8, P<0.01)$. This was a result of increased predation rates experienced by all Bufflehead nests (boxes and cavities) in 1999 (compared to 1997: $\chi_{2}^{2}=8.0, P<0.01$; compared to 1998: $\chi^{2}{ }_{2}=9.9, P<0.01$; Fig. 2a). Within each of the three years, nest fates of Bufflehead nests in boxes and cavities did not differ (1997: $\chi^{2}{ }_{2}=$ 
$0.2, P>0.8 ; 1998: \chi_{2}^{2}=1.1, P>0.5 ; 1999$ : $\chi_{2}^{2}=5.1, P=0.07$ ).

Goldeneye nests in boxes were less successful than Bufflehead nests in boxes through all three years of the study, $\left(1997: \chi^{2}{ }_{2}=6.5, P<0.05\right.$; 1998: $\chi_{2}^{2}{ }_{2}=10.9, P<0.01 ; 1999: \chi_{2}{ }_{2}=7.6, P$ $<0.05)$. There were no differences in cavitynest fates between the two species over the three years $\left(1997: \chi^{2}{ }_{2}=1.8, P>0.3 ; 1998: \chi^{2}{ }_{2}=\right.$ $\left.0.4, P>0.7 ; 1999: \chi_{2}{ }_{2}=1.3, P>0.4\right)$ and both species experienced markedly higher levels of cavity predation in 1999 (Fig. 1a, 2a).

\section{SOURCES OF PREDATION}

The types of predators that preyed on goldeneye nests in boxes differed from those responsible for cavity predation, in all three years (1997: $\chi^{2}{ }_{3}$ $=37.0, P<0.001 ; 1998: \chi_{3}{ }_{3}=9.4, P<0.05$; 1999: $\left.\chi_{3}{ }_{3}=7.8, P<0.05\right)$. The major predator on box nests was black bears (Ursus americanus; Fig. 1b). Hair samples found at the entrances of depredated box nests showed that the main small mammal predators were red squirrels ( $T a$ miasciurus hudsonicus), pine marten (Martes americana), and fishers (Martes pennanti). European Starlings (Sturnus vulgaris) also destroyed goldeneye eggs, apparently in attempts to usurp the nest site. Bears did not prey on cavity nests, but small mammals and starlings were important (Fig. 1b). Small mammal predation increased in cavities in 1999. Aside from black bear predation on box nests, all other predators had similar effects on both nest types in 1998 and 1999.

Predation on Bufflehead nests (boxes and cavities) was low in 1997 ( $n=4$ of 43 nests) and 1998 ( $n=8$ of 75 nests) with the main predators being bears, squirrels, and starlings (Fig. 2b). There were no significant differences in the types or levels of predation between Bufflehead box nests and cavity nests for these two years. In 1999, predation levels increased in both box nests and cavity nests ( $n=32$ of 107 nests, with 26 depredated cavity nests), and small mammals were responsible for nearly all depredations (Fig. 2b).

\section{DISCUSSION}

There were marked differences in the clutch size, nesting success, and patterns of predation of Barrow's Goldeneyes nesting in boxes versus those in natural cavities, but few differences for Bufflehead. In these respects, studies of $\mathrm{Ba}-$ rrow's Goldeneyes that use nest boxes are not representative of birds nesting in natural cavities, whereas those of Bufflehead are more likely to be so.

\section{NEST SITE LOCATION AND PREDATION}

The most obvious physical difference between Barrow's Goldeneye box nests and natural cavity nests is their degree of conspicuousness to predators and parasitizing conspecifics. Goldeneye boxes were concentrated in highly visible locations such as on trees at water or forest edge. Cavity nests, on the other hand, were often abandoned Pileated Woodpecker (Dryocopus pileatus) cavities, which were more dispersed throughout the forest interior and concealed under dense canopy cover. For goldeneyes, the higher conspicuousness of nest boxes to predators may have been responsible for the higher rates of predation and nest parasitism (see below). The most common nest-box predators were bears and small mammals (red squirrels, fishers, and pine martens) and the placement of nest boxes on forest and water edge allowed for easy detection by these animals. Furthermore, cavity nests were significantly higher in the nest tree than box nests, which may have deterred some of the small mammal predators. The height of the nest site within a tree influences the nesting success of many cavity-nesting species. Female Common Goldeneyes and Wood Ducks prefer higher boxes and experience lower predation rates (Prince 1968, Dow and Fredga 1985). Studies of Tree Swallows (Tachycineta bicolor; Rendell and Robertson 1989), European Starlings, Blue Tits (Parus caeruleus), and Marsh Tits ( $P$. palustris; Nilsson 1984b) also show that predation rates decrease with increasing nest height.

The fates of Bufflehead nests in cavities were similar to those of box nests, perhaps because the physical characteristics of the two nest types were not significantly different. For example, Bufflehead cavity nests and box nests were located at equal heights in trees and equal distances from the forest edge, and therefore were equally exposed to predators.

Bufflehead nest sites (boxes and cavities) may experience lower rates of predation than $\mathrm{Ba}$ rrow's Goldeneye sites because their smaller entrance area may exclude medium-sized mammal species. Cavity size is an important variable affecting species occupancy, and individuals that 
select smaller holes may experience reduced predation risk and competition with larger species (Moeed and Dawson 1979, Peterson and Gauthier 1985).

Most comparative studies of box versus cavity nesters have found lower rates of predation and higher fledging success in box nests than in natural sites; examples include the European Starling, Great Tit, Blue Tit, Nuthatch (Sitta europaea; Nilsson 1975), and Tree Swallow (Rendell and Robertson 1993). These results are opposite to ours, which we suspect is due primarily to the presence of bears at our site, a major box predator in our study that has not been reported by others. Bears may be unusual nest-box predators and thus limit the generality of this result. An earlier study of Common and Barrow's Goldeneyes, located only $70 \mathrm{~km}$ southeast of our study, found little to no bear depredation of box nests (J. Eadie, pers. comm.).

\section{CLUTCH SIZE}

Clutches in Barrow's Goldeneye box nests were significantly larger than in cavity nests. Two plausible explanations exist for this result. First, our results suggest that increased levels of conspecific nest parasitism may occur in boxes (also see Eadie 1989), and this may be attributed to their increased degree of conspicuousness. Second, all natural cavities were smaller than boxes and thus the larger basal area of boxes may allow for larger clutches (Nilsson 1984a).

The more likely explanation is that larger clutch sizes in box nests resulted from increased levels of conspecific nest parasitism (Eadie 1989). Like predators, parasitic females can more easily detect artificial nest sites, and our conservative estimates indicated parasitism to be $20 \%$ higher in box nests. Previous studies of goldeneyes estimated nest parasitism to be $8 \%$ higher in box nests than in cavity nests, and 15$61 \%$ higher in Wood Duck box nests (Eadie et al. 1998). Other species that have been reported to experience higher conspecific brood parasitism in box nests than in cavity nests include Black-bellied Whistling-Ducks (Dendrocygna autumnalis; Delnicki 1973), Eastern Bluebirds (Gowaty and Bridges 1991), Barn Swallows (Møller 1987), and European Starlings (Evans 1988).

This is a concern for managers because high levels of parasitism in Wood Duck box nests has frequently led to lower overall reproductive suc- cess at the population level (Haramis and Thompson 1985, Semel et al. 1988). In an extreme case, Semel et al. (1990) found a negative exponential relationship between the number of eggs laid and overall nesting success across six separate Wood Duck populations.

Correlations between floor area and clutch size have been shown in several passerine species, with authors suggesting that basal area may limit the clutch size that can be incubated efficiently (van Balen 1984, Gustafsson and Nilsson 1985). However, nest site volume had no effect on the clutch sizes of Bufflehead (Gauthier 1988), Common Goldeneye (Eriksson 1979), Eastern Bluebirds (Møller 1982), Plain Titmouse (Parus inornatus), House Wren (Troglodytes aedon), and Ash-throated Flycatcher (Myiarchus cinerascens; Purcell et al. 1997). Cavity volume may also influence crowding and induce females to lay smaller clutches (Karlsson and Nilsson 1977, van Balen 1984, Robertson and Rendell 1990). However, since goldeneye and Bufflehead are determinant egg layers and their precocial young remain in the nest site for only two days, crowding is less likely to affect their clutch sizes.

Several other hypotheses also appear unlikely. There is often a negative correlation between laying date and clutch size, but we found no significant differences in initiation dates between boxes and cavities. Female age differences in the different nest types could also affect clutch size (Gauthier and Smith 1987) but we have little information on this as only a few females were of known age in our study. However, we would expect to see timing differences (e.g., nest initiation dates) if females nesting in boxes and cavities differed dramatically in their ages. No differences were seen in this study. Clutch sizes did not vary significantly among ponds, and therefore it is unlikely that variation in local food productivity levels are a factor. It therefore would seem that nest site characteristics such as nest type and location (e.g., conspicuous boxes), and perhaps basal area and volume, influence clutch sizes for Barrow's Goldeneye but not for Bufflehead. Factors such as laying date, female age, food availability, and predation risk are likely to be less important.

For Barrow's Goldeneye, our general findings are similar to those of van Balen et al. (1982), Nilsson (1984a), and Møller (1989) for other species, in that the breeding ecology in artificial 
nest structures differs considerably from that in natural cavities. In contrast, we recorded few physical or biological differences for Bufflehead. Unnaturally low nest predation in nest boxes of other studies appears to be an artifact of nest box designs (Møller 1989). In our study the design and placement of goldeneye nest boxes contributed to artificially high predation rates.

Nest boxes are an important management tool for species experiencing drastic population declines, particularly in areas under intensive forest harvesting, where the availability of natural cavities is limited (Eadie et al. 1998). Nest-box programs are normally considered an effective conservation tool, particularly for cavity-nesting waterfowl (Eriksson 1982, Fredga and Dow 1984, Savard 1986). However, there may be hidden costs to these programs. Extrapolating from our results, we speculate that nest-box programs may in fact create population sinks for Barrow's Goldeneye, attracting large numbers of breeding birds that experience unnaturally high levels of predation and parasitism. As such, recommendations for future nest-box programs under similar circumstances include installing predato guards (specifically, bear deterrents) and placing boxes in less conspicuous locations, farther from ponds or forest edges, in locations similar to those of natural cavities. In our case, preventing bear predation of Barrow's Goldeneye nest boxes would have returned success rates to levels similar to those of natural cavities. Nest parasitism would still continue in conspicuous boxes along edges, but this is less of a concern because abandonment rates, presumably caused in part by egg dumping (as suggested by Eadie 1989), were low. Therefore, we do not consider nest parasitism itself to have had a large effect on the nesting success of Barrow's Goldeneye nests in this study.

On a different note, increasing goldeneye abundance may have a considerable effect on the rest of the waterfowl community considering their extremely aggressive territorial behavior, particularly towards congeners such as Bufflehead (Savard 1986), as well as predicted increases in competition for nest sites with other cavitynesting species (see Nilsson 1984a, Robertson and Rendell 1990). Although well intentioned, nest-box programs have often taken place without consideration for the entire bird community. Few studies have examined the effects of increasing the abundance of selected species on the breeding ecology of other species (Hogstad 1975, Bock et al. 1992). Clearly, more comparative studies involving nest box programs are warranted.

\section{ACKNOWLEDGMENTS}

This research was supported by graduate scholarships to M. Evans from the National Sciences and Engineering Research Council of Canada, Science Council of British Columbia, and Environment Canada's Science Horizons Program. Research support was provided by grants from Forest Renewal British Columbia, the Canadian Wildlife Service, the North American Bluebird Society, Riverside Forest Products Ltd. (Williams Lake), and West Fraser Forest Products Ltd. (Williams Lake). Many of our field assistants were funded by British Columbia's Government Program "First Jobs in Science and Technology". We would like to thank B. Andres, M. Einsworth, B. Rotinsky, S. Schnieder, P. Seccombe-Hett, C. Williams, and P. Yen for valuable assistance in the field. We would also like to thank the Canadian Department of National Defense, and Toosey First Nations for allowing us access to the study area. Thank you to Drs. J. Eadie and G. Gauthier for insightful advice when reviewing the manuscript.

\section{LITERATURE CITED}

Alatalo, R. V., A. Lundberg, and C. Glynn. 1986. Female Pied Flycatchers choose territory quality and not male characteristics. Nature 323:152-153.

Bock, C. E., A. Cruz Jr., M. C. Grant, C. S. Aid, AND T. R. STRONG. 1992. Field experimental evidence for diffuse competition among southwestern riparian birds. American Naturalist 140:815-828.

BOYCE, M. S., AND C. M. PERrINS. 1987. Optimizing Great Tit clutch size in a fluctuating environment. Ecology 68:142-153.

DELNICKI, D. E. 1973. Renesting, incubation behavior and compound clutches of the Black-bellied Tree Duck in southern Texas. M.Sc. dissertation, Texas Tech University, Lubbock, TX.

Dow, H., AND S. FREDGA. 1985. Selection for nest sites by a hole-nesting duck, the Goldeneye (Bucephala clangula). Ibis 127:16-30.

EADIE, J. M. 1989. Alternative reproductive tactics in a precocial bird: the ecology and evolution of brood parasitism in Goldeneyes. Ph.D. dissertation, University of British Columbia, Vancouver, BC, Canada.

Eadie, J., P. Sherman, and B. Semel. 1998. Conspecific brood parasitism, population dynamics, and the conservation of cavity-nesting birds, p. 306340. In T. Caro [ED.], Behavioral ecology and conservation biology. Oxford University Press, New York.

ERIKSSON, M. O. G. 1979. Clutch size and incubation efficiency in relation to nest-box size among Goldeneyes Bucephala clangula. Ibis 121:107109.

ERIKSSON, M. O. G. 1982. Differences between old and newly established Goldeneye (Bucephala clangula) populations. Ornis Fennica 59:13-19. 
ERskine, A. J. 1972. Buffleheads. Canadian Wildlife Service Monograph Series No. 4, Ottawa, ON, Canada.

Evans, P. G. H. 1988. Intraspecific nest parasitism in the European Starling Sturnus vulgaris. Animal Behavior 36:1282-1294.

FredGa, S., AND H. Dow. 1984. Factors affecting the size of a local population of Goldeneye, Bucephala clangula (L.) breeding in Sweden. Swedish Wildlife Research Viltrevy 13:225-255.

Gauthier, G. 1985. A functional analysis of territorial behaviour in breeding Bufflehead. Ph.D. dissertation, University of British Columbia, Vancouver, BC, Canada.

GAUTHIER, G. 1988. Factors affecting nest-box use by Buffleheads and other cavity-nesting birds. Wild life Society Bulletin 16:132-141.

Gauthier, G., and J. N. M. SMith. 1987. Territorial behaviour, nest-site availability, and breeding density in Buffleheads. Journal of Animal Ecolog: 56:171-184.

Gowaty, P. A., AND W. C. BRIDGes. 1991. Nestbox availability affects extra-pair fertilization and conspecific nest parasitism in Eastern Bluebirds, Sialia sialia. Animal Behaviour 41:661-675.

Gustafsson, L., AND S. G. NiLSSON. 1985. Clutch sizc and breeding success of Pied and Collared Flycatchers Ficedula spp. in nest-boxes of different sizes. Ibis 127:380-385.

Hamerstrom, F., F. N. Hamerstrom, and J. Hart. 1973. Nest boxes: an effective management tool for Kestrels. Journal of Wildlife Management 37: 400-403.

Haramis, G. M., And D. Q. Thompson. 1985. Densityproduction characteristics of box-nesting Wood Ducks in a northern greentree impoundment. Journal of Wildlife Management 49:429-436.

HogStAD, O. 1975. Quantitative relations between hole-nesting and open-nesting species within a passerine breeding community. Norwegian Journal of Zoology 23:261-267.

Karlsson, J., AND S. G. NiLsSON. 1977. The influence of nest-box area on clutch size in some hole-nesting passerines. Ibis 119:207-211.

KREBS, J. R. 1971. Territory and breeding density in the Great Tit, Parus major L. Ecology 52:2-22.

Kuitunen, M., AND A. AleKnonis. 1992. Nest predation and breeding success in Common Tree-creepers nesting in boxes and natural cavities. Ornis Fennica 69:7-12.

LACK, D. 1954. The natural regulation of animal numbers. Clarendon Press, Oxford, UK.

MAYFIELD, H. F. 1961. Nesting success calculated from exposure. Wilson Bulletin 73:255-261.

Moeed, A., And D. G. Dawson. 1979. Breeding of Starlings in nest boxes of various types. New Zealand Journal of Zoology 6:613-618.

MøLleR, A. P. 1982. Clutch size in relation to nest size in the Swallow Hirundo rustica. Ibis 124:339343.

MøLLER, A. P. 1987. Intruders and defenders on avian breeding territories: the effect of sperm competition. Oikos 48:47-54.
MøLleR, A. P. 1989. Parasites, predators and nest boxes: facts and artefacts in nest box studies of birds? Oikos 56:421-423.

Nichols, J. D., AND F. A. Johnson. 1990. Wood Duck population dynamics: a review, p. 83-105. In L. H. Frederikson, G. V. Burger, S. P. Havera, D. A. Graber, R. E. Kirby, and T. S. Taylor [EDS.], Proceedings of 1988 North American Wood Duck symposium. St. Louis, MO.

NiLSSON, S. G. 1975. Clutch size and breeding success of birds in nest boxes and natural cavities. Var Fagelvarld 34:207-211.

NiLsson, S. G. 1984a. Clutch size and breeding success of the Pied Flycatcher (Ficedula hypoleuca) in natural tree holes. Ibis 126:407-410.

Nilsson, S. G. 1984b. The evolution of nest-site selection among hole-nesting birds: the importance of nest predation and competition. Ornis Scandinavica 15:167-175.

Nilsson, S. G. 1986. Evolution of hole-nesting in birds: on balancing selection pressures. Auk 103: 432-435.

Peterson, B., and G. Gauthier. 1985. Nest-site use by cavity-nesting birds of the Cariboo Parkland, British Columbia. Wilson Bulletin 97:319-331.

Prince, H. H. 1968. Nest sites used by Wood Ducks and Common Goldeneyes in New Brunswick. Journal of Wildlife Management 32:489-500.

Purcell, K. L., J. Verner, AND L. W. Oring. 1997. A comparison of the breeding ecology of birds nesting in boxes and tree cavities. Auk 114:646-656.

Rendell, W. B., AND R. J. Robertson. 1989. Nest-site characteristics, reproductive success and cavity availability for Tree Swallows breeding in natural cavities. Condor 91:875-885.

Rendell, W. B., AND R. J. Robertson. 1993. Cavity size, clutch size and the breeding ecology of Tree Swallows, Tachycineta bicolor. Ibis 135:305-310.

Robertson, R. J., AND W. B. RENDELl. 1990. A comparison of the breeding ecology of a secondary cavity nesting bird, the Tree Swallow (Tachycineta bicolor), in nest boxes and natural cavities. Canadian Journal of Zoology 68:1046-1052.

SAS Institute InC. 2000. SAS/STAT user's guide. Version 8.1. SAS Institute Inc., Cary, NC.

SAVARD, J. P. L. 1986. Territorial behaviour, nesting success and brood survival in Barrow's Goldeneye and its congers. Ph.D dissertation, University of British Columbia, Vancouver, BC, Canada.

Semel, B., P. W. Sherman, AND S. M. Byers. 1988. Effects of brood parasitism and nest-box placement on Wood Duck breeding ecology. Condor 90:920-930.

Semel, B., P. W. Sherman, And S. M. Byers. 1990. Nest boxes and brood parasitism in Wood Ducks: a management dilemma, p. 163-170. In L. H. Frederikson, G. V. Burger, S. P. Havera, D. A. Graber, R. E. Kirby, and T. S. Taylor [EDS.], Proceedings of 1988 North American Wood Duck symposium. St. Louis, MO.

Thompson, J. E. 1996. Comparative reproductive ecology of female Buffleheads (Bucephala albeola) and Barrow's Goldeneye (Bucephala islandica) in central British Columbia. Ph.D dissertation, University of Western Ontario, London, ON, Canada. 
VAN BALEN, J. H. 1984. The relationship between nestbox size, occupation and breeding parameters of the Great Tit (Parus major) and some other holenesting species. Ardea 72:163-175. van Balen, J. H., C. J. H. Booy, J. A. van Franeker, AND E. R. OsIECK. 1982. Studies on hole-nesting birds in natural nest sites 1 . Availability and occupation of natural nest sites. Ardea 70:1-24. 